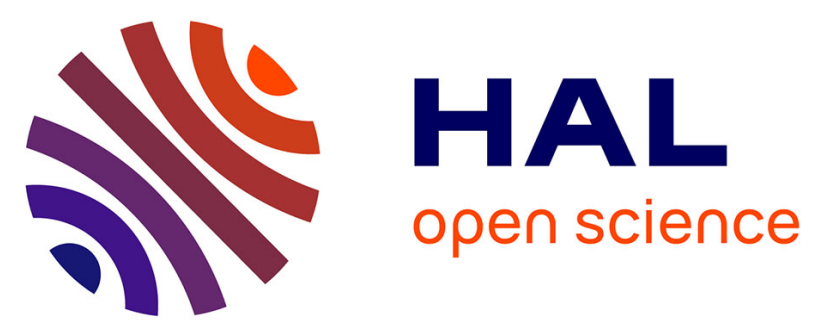

\title{
Preparation of niobium based oxynitride nanosheets by exfoliation of Ruddlesden-Popper phase precursor.
} Ary da Silva Maia, François Cheviré, Valerie Demange, Valérie Bouquet, Mathieu Pasturel, Stéphanie Députier, Ronan Lebullenger, Maryline Guilloux-Viry, Franck Tessier

\section{To cite this version:}

Ary da Silva Maia, François Cheviré, Valerie Demange, Valérie Bouquet, Mathieu Pasturel, et al.. Preparation of niobium based oxynitride nanosheets by exfoliation of Ruddlesden-Popper phase precursor.. Solid State Sciences, 2016, 54, pp.17-21. 10.1016/j.solidstatesciences.2015.11.013 . hal01244820

\author{
HAL Id: hal-01244820 \\ https://hal.science/hal-01244820
}

Submitted on 16 Dec 2015

HAL is a multi-disciplinary open access archive for the deposit and dissemination of scientific research documents, whether they are published or not. The documents may come from teaching and research institutions in France or abroad, or from public or private research centers.
L'archive ouverte pluridisciplinaire HAL, est destinée au dépôt et à la diffusion de documents scientifiques de niveau recherche, publiés ou non, émanant des établissements d'enseignement et de recherche français ou étrangers, des laboratoires publics ou privés. 


\section{Preparation of niobium based oxynitride nanosheets by exfoliation of Ruddlesden-Popper phase precursor.}

$\underline{\text { Ary da Silva Maia }}^{* 1-2}$, François Cheviré ${ }^{2}$, Valerie Demange ${ }^{2}$, Valérie Bouquet $^{2}$, Mathieu Pasturel $^{2}$, Stéphanie Députier ${ }^{2}$, Ronan Lebullenger ${ }^{2}$, Marylline Guilloux-Viry², Franck Tessier $^{2}$.

1 - LACOM - Departamento de Química, Universidade Federal da Paraíba, Cidade Universitária, João Pessoa, PB, CEP 58051-900, Brasil.

2 - Institut des Sciences Chimiques de Rennes, UMR CNRS 6226/ Université de Rennes 1, campus de Beaulieu, 35042 Rennes Cedex, France.

* Corresponding author

\section{ABSTRACT}

A new oxynitride Ruddlesden-Popper phase $\mathrm{K}_{1.6} \mathrm{Ca}_{2} \mathrm{Nb}_{3} \mathrm{O}_{9.4} \mathrm{~N}_{0.6} \cdot 1.1 \mathrm{H}_{2} \mathrm{O}$ was synthesized by the topochemical ammonolysis reaction at $700{ }^{\circ} \mathrm{C}$ from the oxide Dion-Jacobson phase $\mathrm{KCa}_{2} \mathrm{Nb}_{3} \mathrm{O}_{10}$ in the presence of $\mathrm{K}_{2} \mathrm{CO}_{3}$. The oxynitride showed good stability with a little loss of nitrogen, even after a few months of exposure to air. Its crystal structure was solved by Rietveld refinement of X-ray powder diffraction data in space group $\mathrm{P} 4 / \mathrm{mmm}$ and considering a two-phase mixture, due to the difference in the degree of hydration, with $\mathrm{a}=$ 3.894(2) $\AA$ and $\mathrm{c}=17.90(8) \AA$ for the most hydrated phase and $\mathrm{a}=3.927(6)$ and $\mathrm{c}=17.09(2)$ for the less one. Optical band gaps were measured by diffuse reflectance UV-Vis indicating a red shift of Eg to the visible region. The oxynitride layered perovskite was then protonated and exfoliated into nanosheets. TEM images and SAED patterns of the nanosheets proved that exfoliation was successful, showing lattice parameters quite compatible with the Rietveld refinement.

Keywords: Oxynitride, topochemical reaction, Ruddlesden-Popper phase, Dion-Jacobson phase, exfoliation, photocatalyst. 


\section{Introduction}

Layered perovskite oxides have been extensively studied because they exhibit a range of interesting properties including ion-exchange [1], intercalation [2], electronic/protonicconductivity [3], superconductivity [4], dielectric behavior [5], photoluminescence [6] and photocatalytic properties [7-10]. These materials undergo exfoliation upon reaction with several organic bases producing two-dimensional nanosheets [2,9-11] that can be used as useful building blocks for preparing photocatalytic assemblies as a result of their high surface area and high versatility in chemical compositions $[8,12]$.

Several authors $[10,13,14]$ claim that these nanosheets, due to their low thickness $(0.7-1.5 \mathrm{~nm})$, allow that photogenerated electron and hole pairs can reach their surface without encountering obstructions, avoiding "recombination" and "backward reaction". On the other hand some authors $[9,15]$ call attention to compromise between particle size and crystallinity of a given photocatalyst, since the particle size can affect the number of surface reaction sites. According to them, the increase in the density of surface catalytic sites with a smaller particle size can be affected by the larger recombination probability induced by a lower degree of crystallinity.

It has been reported that nanosheets with triple perovskite blocks showed much higher photoactivity for $\mathrm{H}_{2}$ evolution from aqueous 2-propanol solution than two-layer perovskite nanosheets. Such results suggest that the reactivity of holes in the valence band with intercalated molecules varies with the thickness of perovskite layers. [8,9]

Although several works reported these compounds as good ultraviolet (UV) photocatalysts, their large band gaps $(>3 \mathrm{eV})$ inhibit significant photoactivity in the visible spectrum. Due to its lower electronegativity, the substitution of nitrogen for oxygen in such large band gap semi-conductor oxides leads to the insertion of $2 p(\mathrm{~N})$ states above the $2 p(\mathrm{O})$ states at the top of the valence band, thus reducing the band gap and red shifting the 
absorption. Many colored titanium, tantalum or niobium-based perovskite-type oxynitrides have been so far reported in the literature [16] and some such as $\mathrm{LaTiO}_{2} \mathrm{~N}$ or $\mathrm{BaTaO}_{2} \mathrm{~N}$ have been extensively studied as visible-light driven photocatalysts $[17,18]$. Using such strategy in a niobium based layered perovskite Dion-Jacobson phase can cause the reduction of the Bsite transition metal under the reductive ammonia atmosphere used for nitridation reaction [10], but Schottenfeld and co-workers [7] have reported the preparation of colored oxynitride Ruddlesden-Popper phase with band gaps in the visible region from ammonolysis of the Dion-Jacobson phase compounds $\mathrm{RbLaNb}_{2} \mathrm{O}_{7}$ and $\mathrm{RbCa}_{2} \mathrm{Nb}_{3} \mathrm{O}_{10}$ in the presence of excess $\mathrm{Rb}_{2} \mathrm{CO}_{3}$. These new compounds appeared to be unstable versus air oxidation and hydrolysis.

In this work, therefore, the interconversion of an oxide Dion-Jacobson phase $\left(\mathrm{KCa}_{2} \mathrm{Nb}_{3} \mathrm{O}_{10}\right)$ into an oxynitride Ruddlesden-Popper phase $\left(\mathrm{K}_{1+\mathrm{x}} \mathrm{Ca}_{2} \mathrm{Nb}_{3} \mathrm{O}_{10-\mathrm{x}} \mathrm{N}_{\mathrm{x}} \cdot \mathrm{yH} \mathrm{H}_{2} \mathrm{O}\right)$, through topochemical reaction, is studied. This proposition is illustrated in Fig. 1. Moreover, the protonation and exfoliation of the new RP oxynitride are evaluated.

\section{Experimental}

\subsection{Synthesis}

The oxide Dion-Jacobson phase niobate $\mathrm{KCa}_{2} \mathrm{Nb}_{3} \mathrm{O}_{10}(\mathrm{KCN})$ was synthesized by the solid state reaction of $\mathrm{CaCO}_{3}$ (Alfa Aesar 99.95\%), $\mathrm{Nb}_{2} \mathrm{O}_{5}(\mathrm{CBMM} 99.9 \%)$ and $\mathrm{K}_{2} \mathrm{CO}_{3}$ (Acros Organic 99+\%). The reagents were thoroughly mixed in water with a $20 \mathrm{~mol} . \%$ excess of potassium to compensate volatilization during heat treatments. The obtained mixture was dried at $85^{\circ} \mathrm{C}$ and then heated at $1100^{\circ} \mathrm{C}$ for $12 \mathrm{~h}$ in an alumina crucible. The product was water-washed and dried at $110^{\circ} \mathrm{C}$ overnight. The phase purity of this material was verified by X-ray powder diffraction (JCPDS 35-1294).

The oxynitride (KCN-N) was prepared by grinding the Dion-Jacobson phase with a 20 mol. \% stoichiometric excess of $\mathrm{K}_{2} \mathrm{CO}_{3}$ and by reacting the mixture under constant $\mathrm{NH}_{3}$ flow 
of approximately $30 \mathrm{sccm}$ at $700^{\circ} \mathrm{C}\left(5^{\circ} \mathrm{C} \mathrm{min}{ }^{-1}\right)$ for 30 minutes. A portion of the oxynitride was stored in a glove box while the rest was exposed to the atmospheric air and submitted to protonation and exfoliation.

The protonation of the lamellar materials was performed by soaking the samples with a $6 \mathrm{M} \mathrm{HNO}_{3}$ aqueous solution under stirring for 3 days. The acid solution was renewed each day and then the material was then centrifuged, water-washed and dried. This sample was named HCN-N. The exfoliation was performed as reported in the literature $[8,19,20]$, with a tetrabutylammonium hydroxide $(\mathrm{TBAOH})$ aqueous solution at a molar ratio of $\mathrm{TBAOH} / \mathrm{HCa}_{2} \mathrm{Nb}_{3} \mathrm{O}_{10}=10$, and stirred at reflux for about 21 days. After decanting overnight this mixture produced two phases. A solid one that was deposited in the bottom of the flask, named TBACN-N and a colloidal suspension composed by the exfoliated nanosheets, named NS-CN-N.

\subsection{Characterization}

Powder X-ray diffraction (PXRD) was performed by using a Bruker AXS D8 Advance diffractometer with $\theta-2 \theta$ Bragg-Brentano geometry, and monochromatic $\mathrm{Cu} K \alpha 1$ radiation $(\lambda=1.5406 \AA)$. The FullProf software [21] was used to compare the experimental diffraction patterns with the theoretical ones, and to refine the unit cell parameters. Thermogravimetric analyses (TGA) were carried out in a SDT 2960 TA instrument. The powdered samples were heated to $800^{\circ} \mathrm{C}$ in a $\mathrm{Pt}$ crucible in $\mathrm{N}_{2}$ flowing $(3 \mathrm{~L} / \mathrm{h})$ at heating rate of $5^{\circ} \mathrm{C} / \mathrm{min}$. Diffuse reflectance UV-Vis spectroscopy were performed in a Varian Cary 100 spectrometer operating in the range $250-800 \mathrm{~nm}$. The band-gap of the material $(E \mathrm{~g})$ was extracted using the Kubelka-Munk formalism [22]; the error on the $E g$ value is estimated to be $0.05 \mathrm{eV}$. Nitrogen and oxygen contents were determined with a LECO® TC-600 analyzer using the inert gas fusion method and calibrated using Leco® standard oxides and $\mathrm{Si}_{2} \mathrm{~N}_{2} \mathrm{O}$. Scanning electron microscopy (SEM) was performed with a field emission gun Jeol JSM 6310F instrument 
working at $7 \mathrm{kV}$. Chemical composition of the samples was characterized by by energy dispersive X-ray spectroscopy (EDXS) by using a Jeol JSM 6400 instrument operating at 10 $\mathrm{kV}$ equipped with an Oxford Inca EDS system. Transmission electron microscopy (TEM) was performed with $\mathrm{LaB}_{6}$ Philips CM200 $200 \mathrm{kV}$ instrument and a LaB 6 Jeol $2010200 \mathrm{kV}$.

\section{Results and discussion}

After ammonolysis, the white oxide Dion-Jacobson phase $\mathrm{KCN}$ produced a bright deep yellow powder, that became a little clearer after 30 minutes of air exposition (Fig. 2a and b), but remained stable afterwards. The protonation and the exfoliation steps did not promote significant changes in product color as illustrated in Fig. 2c and 2d. Tyndal effect (Fig. 2e) indicates that a colloidal suspension was obtained after exfoliation with TBAOH solution.

As depicted on Fig. 3a, a comparison of the XRD patterns of both oxide DJ phase and oxynitride RP phase confirms the topochemical interconversion during ammonolysis. While KCN presented an orthorhombic symmetry with $\mathrm{Cmcm}$ space group [10,23], KCN-N belongs to $P 4 / \mathrm{mmm}$ space group [7].

The evolution of the crystal structure of the KCN-N phase exposed to air was followed by PXRD analysis (Fig. 3b). The XRD sample was prepared in the glovebox and covered with a Kapton foil to avoid moisturization during the data collection. Then the Kapton foil was removed and the sample was exposed to air and XRD analyses were performed every 30 min for $4 \mathrm{~h}$. The XRD profile of the sample which was not exposed to air confirms the formation of a tetragonal RP phase after nitridation but the diffraction peaks are broad and asymmetric. Upon exposure to air, the RP tetragonal structure type is retained but we observed a progressive evolution of the profile of the diffraction peaks as they became thinner and more symmetrical with time. A slight shift of the Bragg positions is also noticed indicating a progressive increase of the c lattice parameter while the a parameter remains constant. Such unexpected evolution of the lattice parameters is attributed to a rapid hydration of the 
oxynitride RP phase and intercalation of water in the interlamellar space resulting in an elongation of the crystal structure along the $\mathrm{c}$ axis as reported in the literature for some oxide RP phases such as $\mathrm{K}_{2} \mathrm{Ca}_{2} \mathrm{Ta}_{2} \mathrm{TiO}_{10 \cdot 0.8} \mathrm{H}_{2} \mathrm{O}$ [11]. After a couple hours of air exposure, the XRD profile of the sample do not change significantly suggesting a good air stability of the hydrated oxynitride RP phase for several days as confirmed after 24 days by the XRD pattern on Fig. 3a.

The crystal structure was solved based on literature data for the oxynitride Ruddlesden-Popper phase $\mathrm{Rb}_{1.7} \mathrm{Ca}_{2} \mathrm{Nb}_{3} \mathrm{O}_{9.3} \mathrm{~N}_{0.7} \cdot 0.5 \mathrm{H}_{2} \mathrm{O}$ [7]. A few reflections corresponding to $\mathrm{KNbO}_{3}$ impurity phase were observed in XRD patterns. The Rietveld refinement was performed on a sample kept for six months in a pillbox and we noticed the appearance of shoulders on some diffraction peaks, in particular for 001 lines at the low angles region. This suggests a small decrease of the c lattice parameter for some of the crystallites attributed to an evolution of the degree of hydration in some parts of the sample (Fig. 4). So the Rietveld structural refinement of the oxynitride pattern was made in space group $\mathrm{P} 4 / \mathrm{mmm}$ considering a mixture of two RP phases with close cell parameters with slightly different c lattice parameter. The more hydrated phase $(\mathrm{KCN}-\mathrm{N} 1)$ showed cell parameters a $=3.894(2) \AA$ and c $=17.90(8) \AA$, while the second phase $(\mathrm{KCN}-\mathrm{N} 2)$ crystallizes with $\mathrm{a}=3.927(6) \AA$ and $\mathrm{c}=$ 17.09(2) $\AA$. In this refinement, it was assumed that all nitrogen atoms were uniformly distributed over the all the lattice anions sites and all $\mathrm{O}^{2-} / \mathrm{N}^{3-}$ sites were refined as oxygen atoms [7]. The refinement converged reasonably well to give $\mathrm{R}_{\mathrm{p}}=14.0 \%, \mathrm{R}_{\mathrm{wp}}=17.9 \%, \mathrm{R}_{\exp }$ $=10.85 \%$ and $\mathrm{Chi} 2=2.72$. It is understood that high reliability factors are not only due to the presence of the perovskite impurity but particularly to the low crystallinity of the less hydrated phase $(\mathrm{KCN}-\mathrm{N} 2)$. The results are in reasonable agreement with those reported in the literature for other RP phases [7,24]. 
Kubelka-Munk method [22] was used to the calculation of band gap energies (Eg) from UV-Vis diffuse reflectance spectra (Fig. 5). KCN-N and HCN-N samples had lower band gap energies relative to parent DJ oxide with Eg shifted to the visible region.

The TGA pictured on Fig. 6 indicates that while the KCN was thermally stable in the measured temperature range, the oxynitrides suffer weight loss, compatible with the literature [7,25]. At lower temperatures (up to $100{ }^{\circ} \mathrm{C}$ ) evaporation of surface adsorbed or some interlayer water was observed. The second weight loss above $200{ }^{\circ} \mathrm{C}$ for the samples $\mathrm{HCN}-\mathrm{N}$ and TBACN-N was attributed to a dehydroxylation. The sharp weight loss around $150{ }^{\circ} \mathrm{C}$ for TBACN-N sample was compatible with the oxidative decomposition of TBA cations, as observed in the literature [26].

Water, nitrogen, potassium and niobium contents of samples obtained by combining the $\mathrm{TGA}^{\mathrm{a}}$, elemental analyses ${ }^{\mathrm{b}}$ and $\mathrm{EDS}^{\mathrm{c}}$ results are summarized in Table 1.

If we consider a full topochemical conversion of the oxide DJ phase $\mathrm{KCa}_{2} \mathrm{Nb}_{3} \mathrm{O}_{10}$ into an oxynitride RP phase with the theoretical composition $\mathrm{K}_{2} \mathrm{Ca}_{2} \mathrm{Nb}_{3} \mathrm{O}_{9} \mathrm{~N}$, the as-prepared $\mathrm{RP}$ oxynitride presented a lower than expected nitrogen content. This is explained by a partial insertion of additional potassium within the interlayer as revealed by EDS analysis that is compatible with the $\mathrm{K}_{1+\mathrm{x}} \mathrm{Ca}_{2} \mathrm{Nb}_{3} \mathrm{O}_{10-\mathrm{x}} \mathrm{N}_{\mathrm{x}}$ chemical composition. It can also be concluded that the protonation step of RP oxynitride occurred satisfactorily, in agreement with previous results for the protonation of $\mathrm{DJ}$ phase $\mathrm{KCa}_{2} \mathrm{Nb}_{3} \mathrm{O}_{10}$ [8,27], where residual $\mathrm{K} / \mathrm{Nb}$ ratios of 0.01-0.03 were reported. Furthermore protonation was responsible for partial elimination of nitrogen, although it still remains. From the results of Table 1 it was possible to propose the following molecular formulas for the $\mathrm{KCN}-\mathrm{N}$ and $\mathrm{HCN}-\mathrm{N}$ compounds respectively: $\mathrm{K}_{1.6} \mathrm{Ca}_{2} \mathrm{Nb}_{3} \mathrm{O}_{9.4} \mathrm{~N}_{0.6} \cdot 1.1 \mathrm{H}_{2} \mathrm{O}$ and $\mathrm{H}_{1.3} \mathrm{Ca}_{2} \mathrm{Nb}_{3} \mathrm{O}_{9.7} \mathrm{~N}_{0.3} \cdot 0.9 \mathrm{H}_{2} \mathrm{O}$. 
Fig. 7a-d show SEM images of $\mathrm{KCN}, \mathrm{KCN}-\mathrm{N}, \mathrm{HCN}-\mathrm{N}$ and TBACN-N samples. These micrographs confirm a typical layer structure stacked layer by layer, that has considerably evolved depending on the processing it has undergone.

After the treatment in tetrabutylammonium hydroxide aqueous solution, the exfoliated particles (NS-CN-N) have a very thin sheet shape with few hundred nanometers in lateral dimensions as observed in the TEM micrograph of Fig. 8.

The corresponding selected-area electron diffraction (SAED) pattern of the NS-CN-N sample shows that the material still retains crystallinity. The pattern corresponds to the [001] orientation, fully compatible with the $\mathrm{P} 4 / \mathrm{mmm}$ space group of a RP phase. The determined lattice parameter is in agreement with the Rietveld refinement result ( $\mathrm{a}=3.9 \AA$ ) .

Several authors have already worked with the protonation and exfoliation of RP phase oxides $[11,24,28,29]$. In general Ruddlesden-Popper phases are known to not intercalate organic bases [29] and without this ability of intercalation, the exfoliation cannot occur. According to Gopalakrishnan and co-workers this inability would be structural in nature, resulting from the staggered perovskite layers rather than the intrinsic acidity of the interlayer protons. On the other hand Schaak and Mallouk [11] concluded, by evaluating the influence of the acidity of different phases, that RP tantalates are more reactive with bases than their titanate or niobate counterparts. In their results Ruddlesden-Popper titanates and titanoniobates have weakly acidic interlayer protons and exfoliate only to a limited extent. Nevertheless regarding the literature there is so far no examples of RP phase oxynitrides successfully submitted to these reactions.

\section{Conclusions}

The topochemical ammonolysis of the Dion-Jacobson oxide $\mathrm{KCa}_{2} \mathrm{Nb}_{3} \mathrm{O}_{10}$ in the presence of $\mathrm{K}_{2} \mathrm{CO}_{3}$ succeeded in the synthesis of the Ruddlesden-Popper phase oxynitride $\mathrm{K}_{1.6} \mathrm{Ca}_{2} \mathrm{Nb}_{3} \mathrm{O}_{9.4} \mathrm{~N}_{0.6} \cdot 1.1 \mathrm{H}_{2} \mathrm{O}$. The oxynitride showed good stability even after a long time of 
exposure to air. This material was successful protonated and exfoliated into nanosheets with reasonable cristallinity. This result fits this oxynitride as potential building blocks to new nanostructured materials. The measured band gap also makes these materials promising photocatalysts in the visible region of spectrum.

\section{Acknowledgments}

This work was supported by CAPES - Brazilian Federal Agency for Support and Evaluation of Graduate Education within the Ministry of Education of Brazil. The authors acknowledge F. Gouttefangeas and L. Joanny for SEM images and EDS analyses performed at CMEBA (ScanMAT, University of Rennes 1). TEM experiments were conducted at THEMIS facilities (ScanMAT, University of Rennes 1). CMEBA and THEMIS received a financial support from the Region Bretagne, Rennes Metropole and the European Union (CPER-FEDER 2007 - 2014).

\section{References}

[1] Y. Kobayashi, M. Tian, M. Eguchi, T.E. Mallouk, J. Am. Chem. Soc. 131 (2009) 9849.

[2] M.A. Bizeto, A.L. Shiguihara, V.R.L. Constantino, J. Mat. Chem. 19 (2009) 2512.

[3] Y. Kobayashi, J.A. Schottenfeld, D.D. Macdonald,T.E. Mallouk, J. Phys. Chem. C 111 (2007) 3185.

[4] M. Kato, Y. Imai, T. Kajita, Y. Takarabe, T. Minakawa, K. Nemoto, H. Tezuka, T. Nojia, Y. Koike, Mater. Sci. Eng. B 148 (2008) 53.

[5] S.-H. Kweon, M. Im, G. Han, J.-S. Kim, S. Nahm, J.-W. Choi, S.-J. $\quad$ Hwang, J. Eur. Ceram. Soc. 33 (2013) 907.

[6] S. Ida, C. Ogata, M. Eguchi, W.J. Youngblood, T.E. Mallouk, Y. Matsumoto, J. Am. Chem. Soc. 130 (2008) 7052.

[7] J.A. Schottenfeld, A.J. Benesi, P.W. Stephens, G. Chen, P.C. Eklund, T.E. Mallouk, J. Solid State Chem. 178 (2005) 2313

[8] K. Maeda, T.E. Mallouk, J. Mater. Chem. 19 (2009) 4813.

[9] K. Maeda, M. Eguchi, W.J. Youngblood, T.E. Mallouk, Chem. Mater. 21 (2009) 3611. 
[10] S. Ida, Y. Okamoto, S. Koga, H. Hagiwara, T. Ishihara, RSC Adv. 3 (2013) 11521.

[11] R.E. Schaak, T.E. Mallouk, Chem. Mater. 12 (2000) 3427.

[12] Y. Ebina, N. Sakai, T. Sasaki, J. Phys. Chem. B 109 (2005) 17212.

[13] R.E. Schaak, T.E. Mallouk, Chem. Mater. 12 (2000) 2513.

[14] Y. Okamoto, S. Ida, J. Hyodo, H. Hagiwara and T. Ishihara, J. Am. Chem. Soc., 133 (2011) 18034.

[15] B. Ohtani, Y. Ogawa, S. Nishimoto, J. Phys. Chem. B 101 (1997) 3746.

[16] R. Aguiar, D. Logvinovich, A. Weidenkaff, A. Rachel, A. Reller, S. G. Ebbinghaus, Dyes and Pigments 76 (2008) 70.

[17] A. Kasahara, K. Nukumizu, T. Takata, J. N. Kondo, M. Hara, H. Kobayashi, K. Domen, J. Phys. Chem. B 107 (2003) 791

[18] K. Maeda, K. Domen, J. Phys. Chem. C 111 (2007) 7851-7861].

[19] Y. Chen, X. Zhao, H. Ma, S. Ma, G. Huang, Y. Makita, X. Bai, X. Yang, J. of Solid State Chem. 181 (2008) 1684.

[20] E.C. Carroll, O.C. Compton, D. Madsen, F.E. Osterloh, D.S. Larsen, J. Phys. Chem. C 112 (2008) 2394.

[21] J. Rodriguez-Carvajal, Physica B 192 (1993) 55.

[22] D. Kubelka, L. Munk, Z. Teck. Physik. 12 (1931) 593.

[23] H. Fukuoka, T. Isami, S. Yamanaka, J. Solid State Chem. 151 (2000) 40.

[24] R.E. Schaak, T.E. Mallouk, J. Solid State Chem. 155 (2000) 46.

[25] C. Sun, P. Peng, L. Zhu, W. Zheng, Y. Zhao, Eur. J. Inorg. Chem. 24 (2008) 3864.

[26] N.-R. Lee, H. Jung, J. Phys.Chem. Solids 73 (2012) 1473.

[27] M. Fang, C.H. Kim, T.E. Mallouk, Chem. Mater. 11 (1999), 1519.

[28] J. Gopalakrishnan, S. Uma, V. Bhat, Chem. Mater. 5 (1993) 132.

[29] S. Uma, A.R. Raju, J. Gopalakrishnan, J. Mater. Chem. 3 (1993) 709. 


\section{Figures and Tables}

Figure 1: Synthetic scheme for the topochemical interconversion of $\mathrm{KCa}_{2} \mathrm{Nb}_{3} \mathrm{O}_{10}$ into the corresponding Ruddlesden-Popper oxynitride. $\mathrm{O}_{\mathrm{w}}$ are the lattice water oxygens atoms.

Figure 2: Physical appearance of (a) KCN precursor, (b) KCN-N oxynitride, (c) HCN-N protonated oxynitride, (d) TBACN-N solid and (e) Tyndal effect on NS-CN-N colloidal suspension.

Figure 3 : PXRD of (a) KCN and KCN-N samples, (b) KCN-N sample after different times of air exposition. (* $\mathrm{KNbO}_{3}$ impurity).

Figure 4 : FullProf refinement of X-ray powder diffraction data for KCN-N showing observed (top black solid line) and calculated (top red circles) intensities, difference (bottom blue solid line) and allowed Bragg reflections (tick marks).

Figure 5 : Diffuse reflectance UV-visible spectra of $\mathrm{KCN}, \mathrm{KCN}-\mathrm{N}$ and $\mathrm{HCN}-\mathrm{N}$ samples and values of energy band gap (inset).

Figure 6: TGA of KCN, KCN-N, HCN-N and TBACN-N samples.

Figure 7 : SEM images of (a) KCN, (b) KCN-N, (c) HCN-N and (d) TBACN-N powders.

Figure $8:$ a) TEM brightfield image of a square-shaped layered NS-CN-N oxynitride nanosheet. b) Corresponding electron diffraction pattern along the [001] zone axis.

Table 1 : Water, nitrogen, potassium and niobium contents (per formula unit) of $\mathrm{KCN}, \mathrm{KCN}-$ $\mathrm{N}$ and HCN-N samples. 
Figure 1

$\mathrm{KCa}_{2} \mathrm{Nb}_{3} \mathrm{O}_{10}$

Dion-Jacobson phase

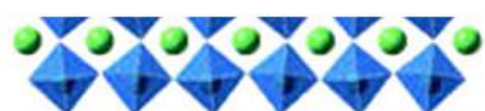

- 0 ○ 0 ○ 00

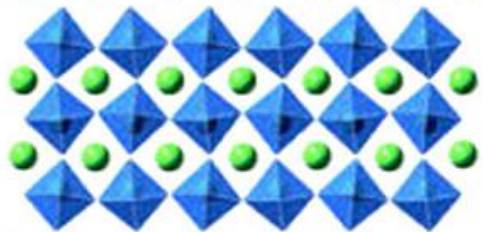

000000

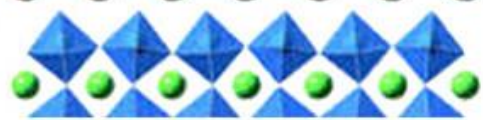

$\mathrm{NbO}_{6}$ or $\mathrm{Nb}(\mathrm{O} / \mathrm{N})_{6}$

- $\mathrm{K}$
$\mathrm{K}_{1+\mathrm{x}} \mathrm{Ca}_{2} \mathrm{Nb}_{3} \mathrm{O}_{10-\mathrm{x}} \mathrm{N}_{\mathrm{x}} \cdot \mathrm{yH}_{2} \mathrm{O}$

Ruddlesden-Popper phase

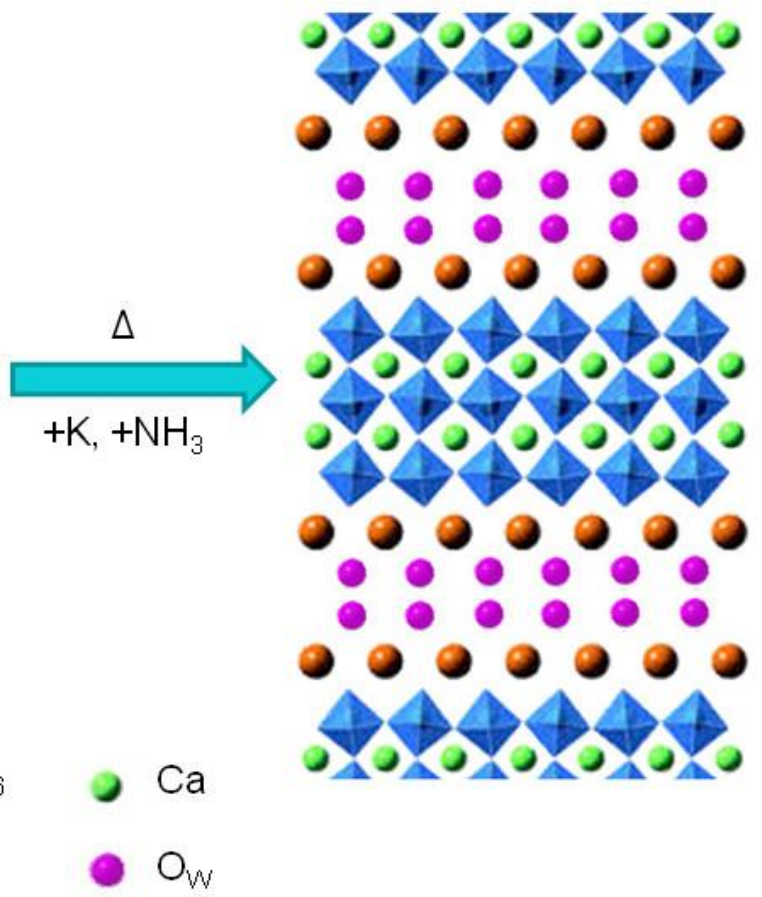


Figure 2

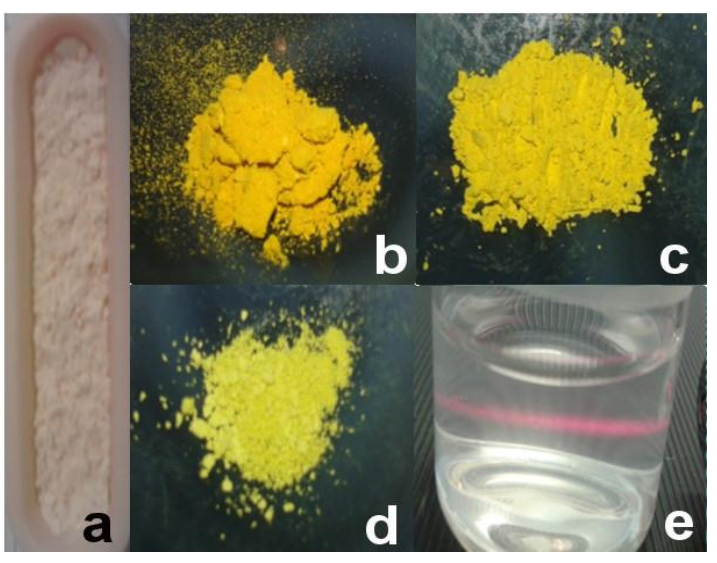


Figure 3
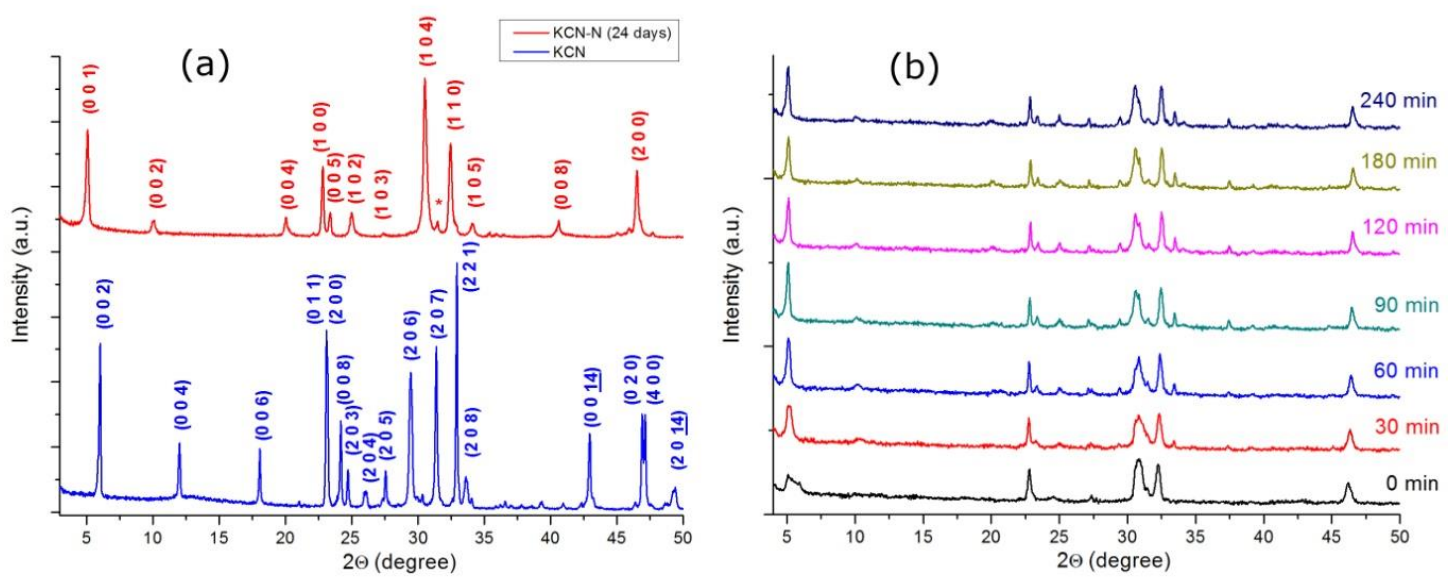
Figure 4

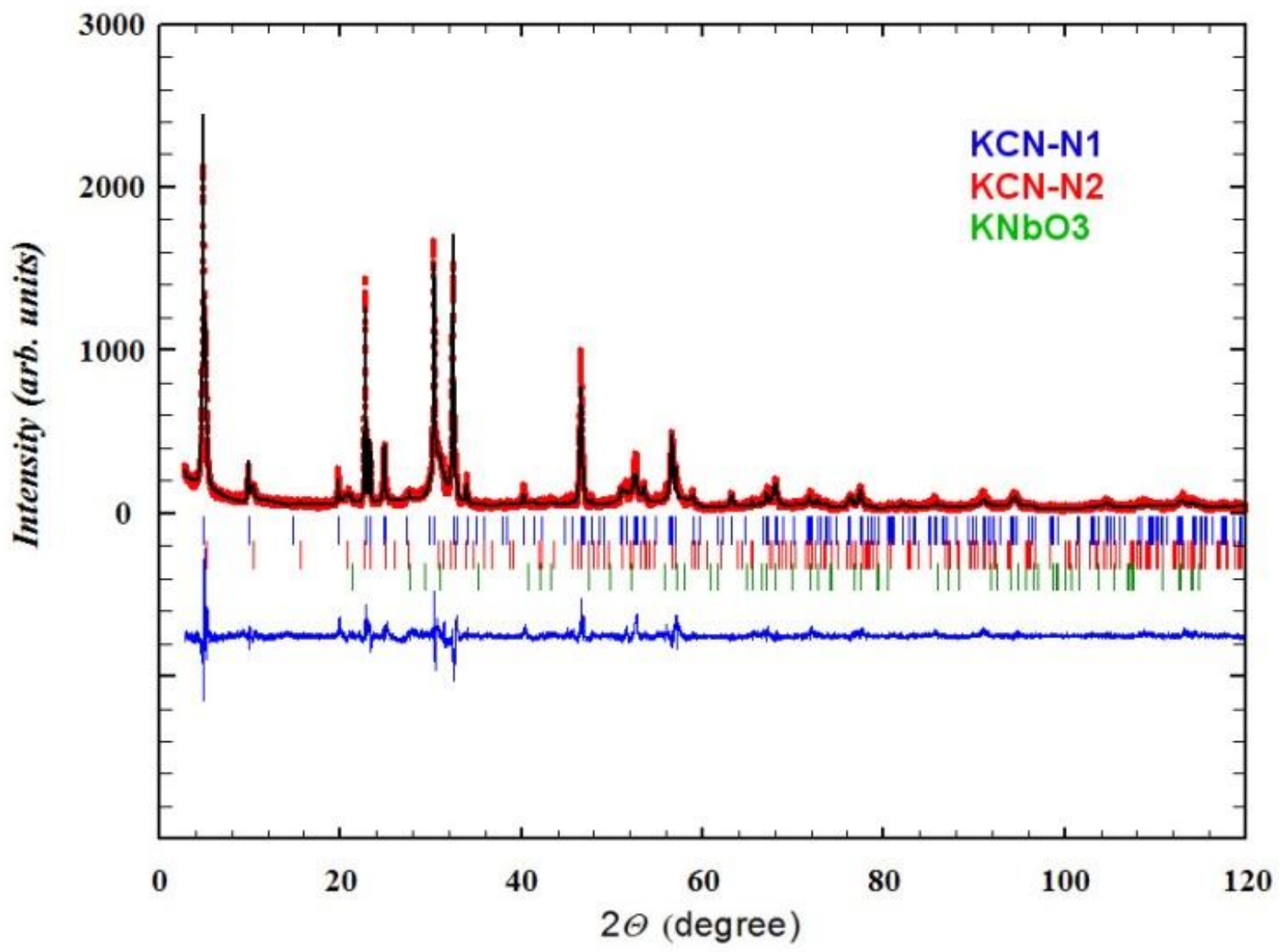


Figure 5

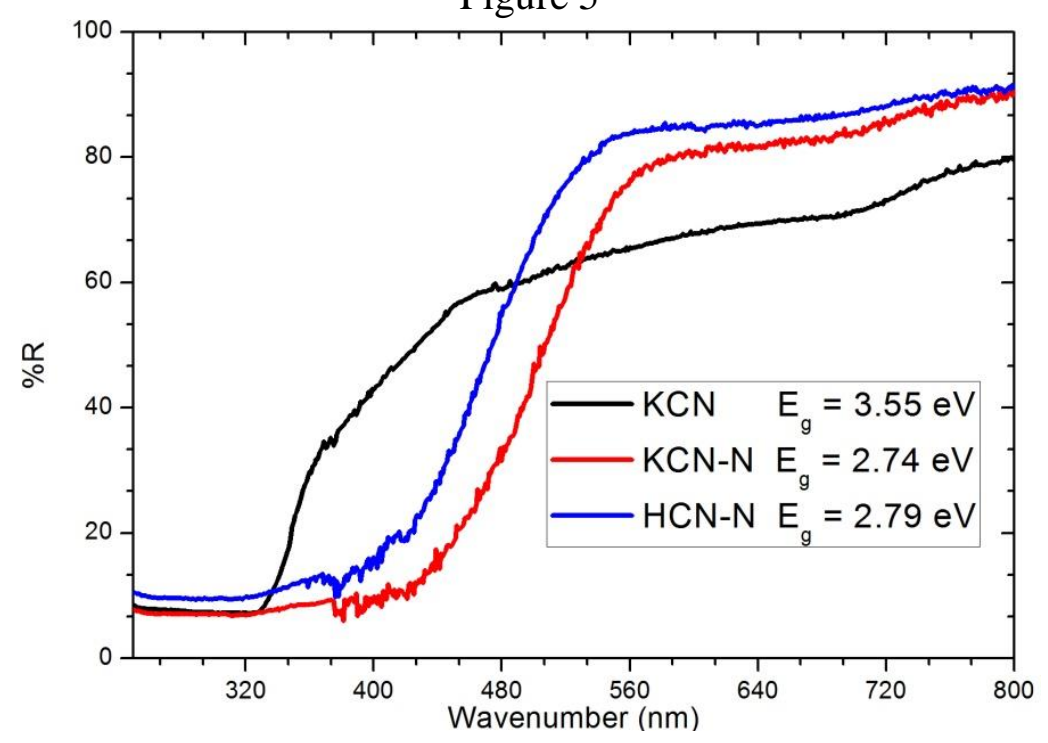


Figure 6

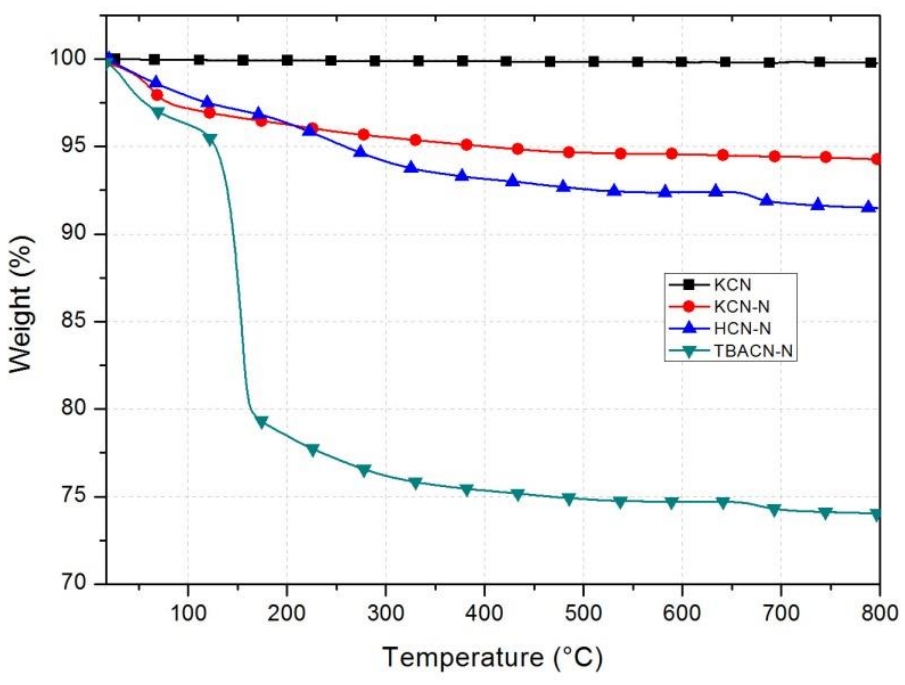




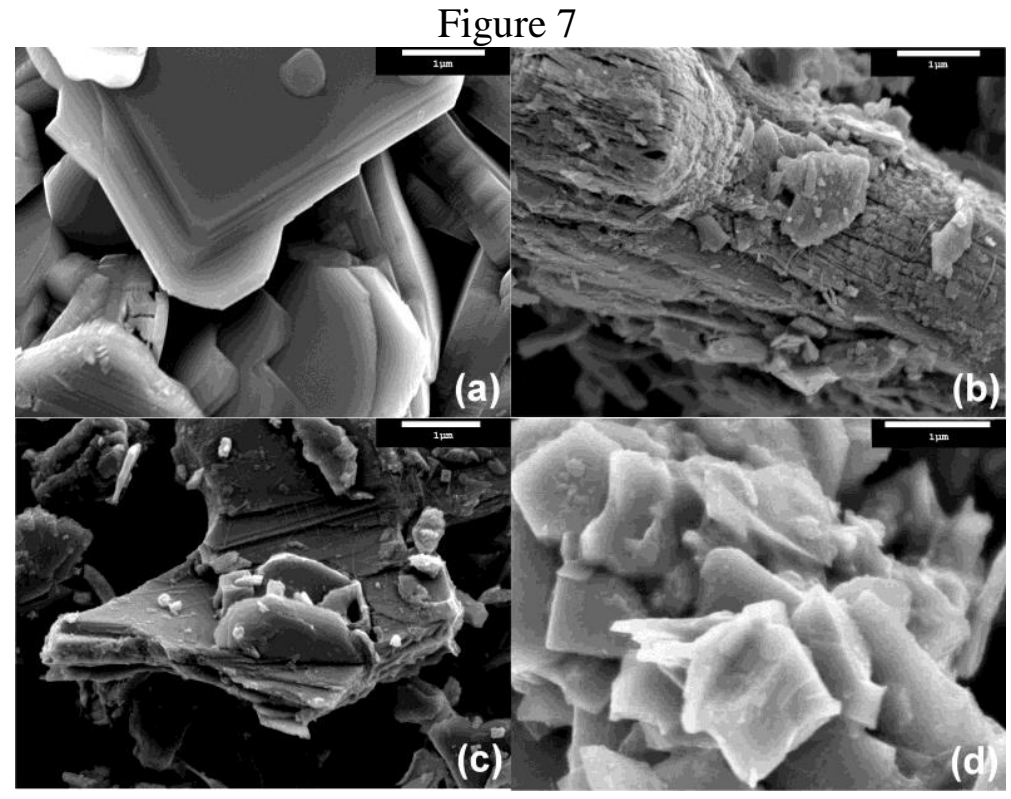



Figure 8

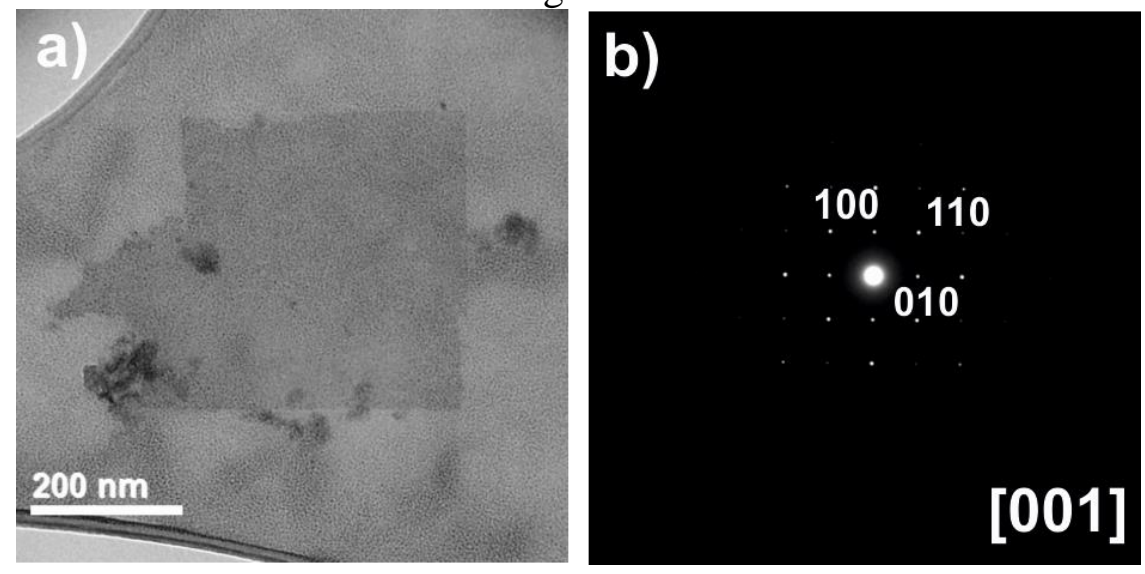


Table 1

\begin{tabular}{lcccc}
\hline \multicolumn{1}{c}{ Sample } & $\begin{array}{c}\text { Mols } \\
\text { water }^{\mathrm{a}}\end{array}$ & $\begin{array}{c}\text { Mols } \\
\text { nitrogen }^{\mathrm{b}}\end{array}$ & $\begin{array}{c}\text { Mols } \\
\text { potassium }^{\mathrm{c}}\end{array}$ & $\begin{array}{c}\text { Mols } \\
\text { niobium }^{\mathrm{c}}\end{array}$ \\
\hline KCN & $0.00 \pm 0.10$ & $0^{*}$ & $1.09 \pm 0.08$ & $2.93 \pm 0.08$ \\
KCN-N & $1.10 \pm 0.10$ & $0.58 \pm 0.02$ & $1.52 \pm 0.08$ & $2.97 \pm 0.08$ \\
HCN-N & $0.86 \pm 0.10$ & $0.26 \pm 0.02$ & $0.08 \pm 0.08$ & $3,12 \pm 0.08$ \\
\hline * Not measured & & & &
\end{tabular}

